\title{
Ability of Short wavelength automated perimetry to detect visual field changes in diabetic patients
}

\section{Mohamed Ateto Hamed ${ }^{\mathrm{a}}$, Ahmed Hasan Aldghaimy ${ }^{\mathrm{b}}$, Hany Omer Elsedfy ${ }^{\mathrm{c}}$, Ayat Yosef Mohamed}

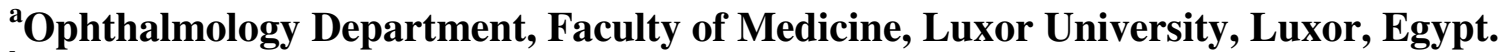

${ }^{b}$ Ophthalmology Department, Faculty of Medicine, South Valley University, Qena, Egypt.

'Ophthalmology Department, Faculty of Medicine, Assiut University, Assiut, Egypt.

\begin{abstract}
Background: Globally, diabetes-related eye illness is the primary cause of visual impairment due to cataracts or retinopathy. The two most used visual field testing modalities in clinical practice are standard automated white-on-white (W-W) perimetry (SAP) and short wave length automated perimetry (SWAP).

Objectives: To compare the value of short wave length automated perimetry SWAP (blue on yellow in contrast) to standard automated perimetry SAP in detecting changes in retinal sensitivity in diabetic individuals with or without retinopathy.

Patients and methods: Forty eyes of forty patients divided into two groups, group (A) diabetic patients (20 eyes) without diabetic retinopathy and group (B) diabetic patients (20 eyes) with early diabetic retinopathy. The perimetry was done for all patients into two perimetry examination. First visit was for SAP and second visit was for SWAP.

Results: In SAP, group II's MD (mean deviation) was considerably lower than group I's $(\mathrm{P}=0.003)$. In SWAP, the MD in group II was considerably lower than in group I $(\mathrm{P}=0.001)$. MD was substantially lower in SWAP than SAP in group I $(\mathrm{P}=0.00009)$. In group II, the same results were obtained.

Conclusions: In terms of distinction, the SWAP approach proved more sensitive and informative than the SAP technique.
\end{abstract}

Key words: SWAP,SAP ,VF ,DM.

\section{Introduction}

Globally, disease secondary to diabetes could be a leading reason behind disablement as a result of cataracts or retinopathy. (Klein et al., 2007). Diabetic retinopathy may be a progressive disease that results from vascular injury thanks to chronic hyperglycemia. It is the leading reason for blindness in adults and is typically asymptomatic until late stages. (Ryan et al .2010).

Standard automated white-on-white (WW) perimetry (SAP), and short wavelength automated perimetry (SWAP) are two prevailing sight view testing technologies employed in clinical practice. (Liu et al ., 2011).

Visual field testing usually performed with SAP with a homogenous white target projected on an identical white background. The W-W stimulus has broadband characteristics that activate the spectrum of retinal ganglion cells within the tested retina. (Bayer et al .,2002).

Blue-yellow perimetry isolates and measures blue cone function (Sample et al.,1986). The carefully chosen bright yellow background desensitizes the green and red cones, and has little effect on blue cone function (Sample et al.,1993). 
Hamed et al (2022)

The narrow band 440 nanometer blue stimulus falls right the height sensitivity of blue cones (Johnson et al .,1993). The principle of this method is selective testing of the shortwavelength sensitive (SWS) cone mediated mechanisms.(Sample et al.,1990). Blue-onyellow automated perimetry, which uses a shortwavelength blue stimulus on a high luminance

\section{Patients and methods}

Patients were separated into two groups. Group (I) diabetic patients (20 eyes) without diabetic retinopathy and group (II) diabetic patients (20 eyes) with early diabetic retinopathy

\section{Criteria for Acceptance}

The participants ranged in age from 16 to 55 years old

Patients with type 1 or type 2 diabetes

\section{Criteria for exclusion:}

The patient had glaucoma, opaque media, or advanced diabetic retinopathy, as well as severe visual loss.

- For both blue-on-yellow and whiteon-white(achromatic)conditions, a visual field analyzer (Humphrey Field Analyzer HFA II Series, Carl Zeiss Meditec, model 750; San Leandro, CA) was employed.

- For achromatic perimetry, the stimulus size was Goldmann III ( 0.438 of visual angle) and for blueon-yellow perimetry, Goldmann V
SVU-IJMS, 5(1):210-218

yellow background, is more sensitive in detecting early abnormalities than is standard achromatic perimetry, which uses a white stimulus on white background.(Hart et al.,1990). We aimed to determine the value of SWAP (blue on yellow contrast) and SAP in detecting changes in retinal sensitivity in diabetic patients with or without retinopathy.

(1.88 of visual angle). For achromatic perimetry, the background was a ten $\mathrm{cd} / \mathrm{m} 2$ broadband white, and for blue-onyellow perimetry, a $100 \mathrm{~cd} / \mathrm{m} 2$.

- All patients were divided into two perimetry examinations. The initial visit was for SAP.

\section{Ethical consideration}

The research protocol was created in compliance with the Declaration of Helsinki and the Council of Medical Research's Guidelines on Ethical Biomedical Research on Human Subjects. The research was authorized by the Institutional Ethics Committee. Prior to their enrolment, all patients provided written informed permission.

\section{Statistical analysis}

Continuous variables were characterized by mean and variance, while categorical variables were described by number and percent ( $\mathrm{N}$, percent) (Mean, SD). The chi-square test is used to compare categorical data. Statistical significance was defined as a two-tailed p 0.05. To determine 
Hamed et al (2022)

the probability, use the Kaplan-Meier curve. The IBM SPSS 20.0 program was used to conduct all

\section{Results}

Forty eyes of forty patients were recruited for the study, The mean age was $39.60 \pm 11.99$ years (ranged from 20:55 years) in group I. The mean age was 39.60 \pm 11.99 years (ranged from 20:55 years) in group I as demonstrated in table 1 and figure 1 . In group II, the average age was 43.9512.27 years (with a range of 20:55 years). There was no statistically significant difference between the two groups ( $\mathrm{p}=0.221 .1)$. There were 24 men (60\%) and 16 women (40\%) in the group (40 percent ). as shown in table 2 and figure 2. in accordance with sex The difference between the two groups was not statistically significant $(\mathrm{p}=$ 1.000).
SVU-IJMS, 5(1):210-218

of the analyses.

As shown in table 3 and figure 3, the average duration of diabetes in our study was 4.10 2.43 SD years in group I and 6.80 3.32 SD years in group II. The difference between the two groups was statistically significant $(\mathrm{p}$ value $=$ $0.008)$.

Group II had a considerably lower MD $(\operatorname{tab} 1)$ in SAP than group I $(p$ value $=0.003)$. In SWAP, the MD in group II was considerably lower than in group I ( $\mathrm{p}$ value $=0.001)$. MD was substantially lower in SWAP than SAP in group I $(\mathrm{P}=0.00009)$. Group II follows the same path as group I. Table 4 and Figure 4 demonstrate this.

Table 1. Age in both groups

\begin{tabular}{|l|c|c|c|}
\hline \multicolumn{1}{|c|}{ Age (years) } & $\begin{array}{c}\text { Group I } \\
(\mathbf{n = 2 0})\end{array}$ & $\begin{array}{c}\text { Group II } \\
(\mathbf{n = 2 0})\end{array}$ & P-value \\
\hline Mean \pm SD & $39.60 \pm 11.99$ & $43.95 \pm 12.27$ & \multirow{2}{*}{0.221} \\
\hline Median (Range) & $40.0(20.0-55.0)$ & $50.0(20.0-55.0)$ & \\
\hline
\end{tabular}

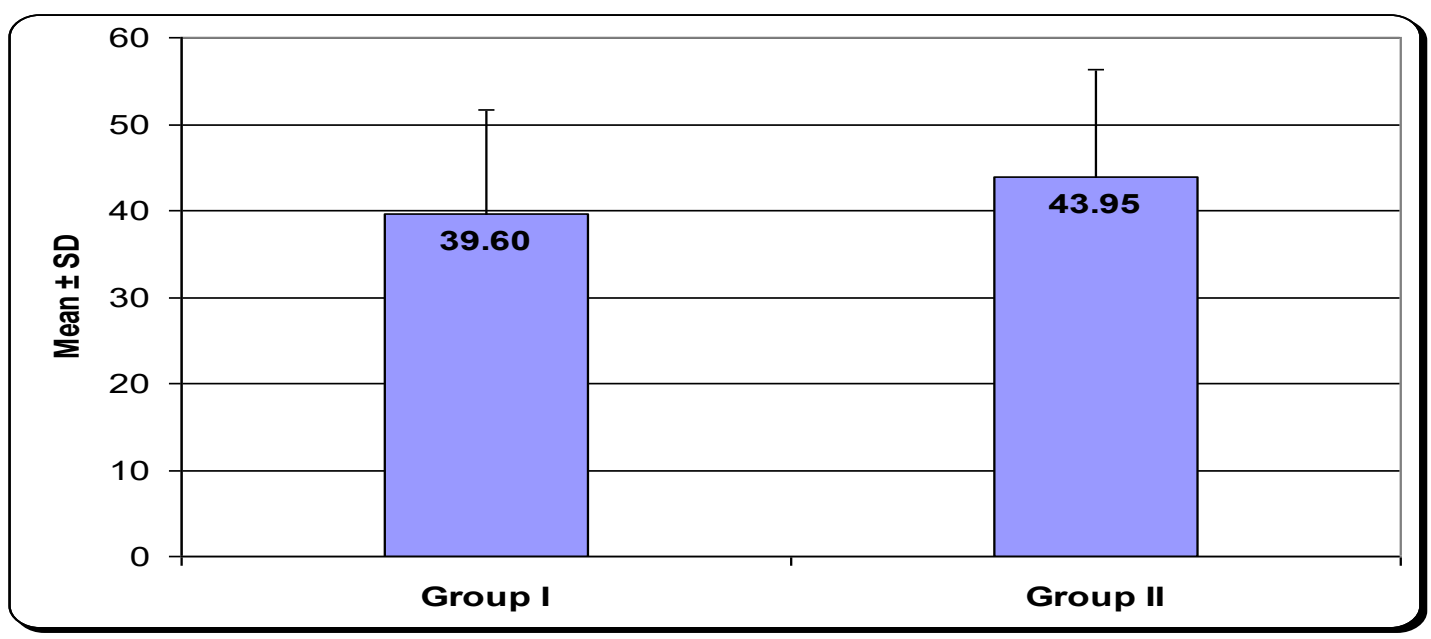

Fig.1. Age in both groups 
Table 2. Sex distribution in both groups

\begin{tabular}{|l|c|c|c|c|c|}
\hline \multirow{2}{*}{ Sex } & \multicolumn{2}{|c|}{$\begin{array}{c}\text { Group I } \\
(\mathbf{n = 2 0})\end{array}$} & \multicolumn{2}{c|}{$\begin{array}{c}\text { Group II } \\
(\mathbf{n = 2 0 )}\end{array}$} \\
\cline { 2 - 5 } & No. & P-value \\
\cline { 1 - 5 } Male & 12 & 60.0 & No. & \% & \multirow{2}{*}{1.000} \\
\hline Female & 8 & 40.0 & 8 & 40.0 & \\
\hline
\end{tabular}

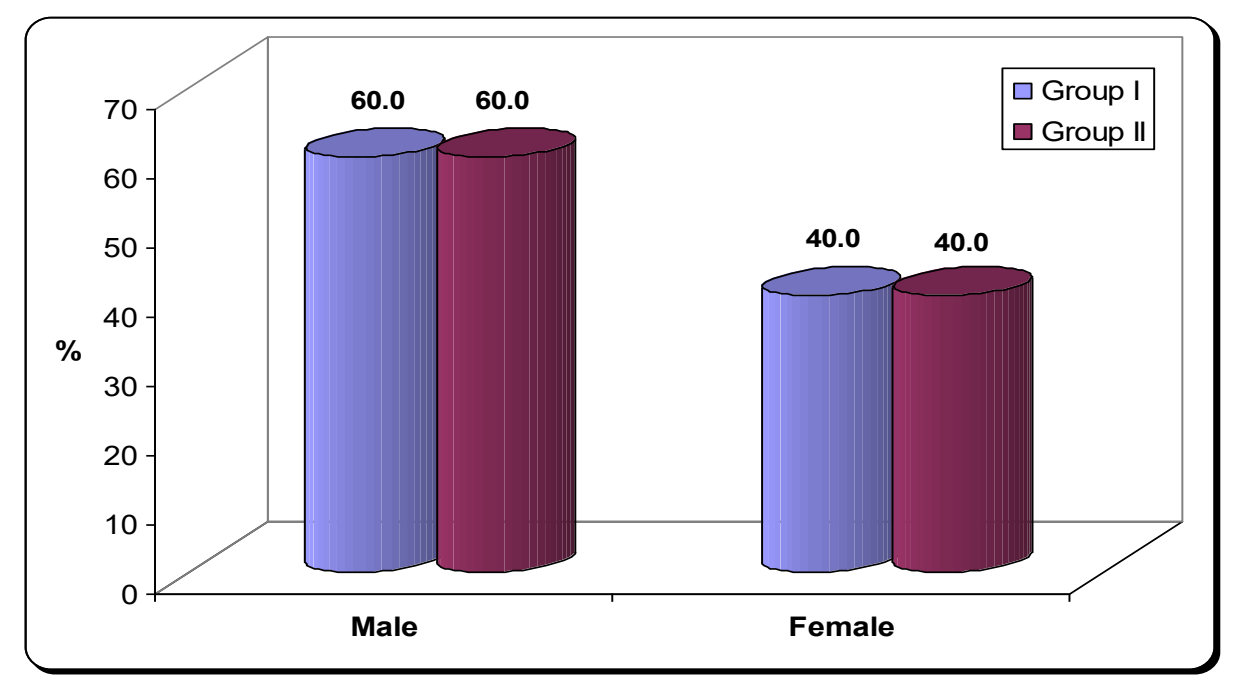

Fig.2. Sex distribution in both groups

Table 3. Duration of disease in both groups

\begin{tabular}{|l|c|c|c|}
\hline Duration of disease (years) & $\begin{array}{c}\text { Group I } \\
(\mathbf{n = 2 0})\end{array}$ & $\begin{array}{c}\text { Group II } \\
(\mathbf{n = 2 0})\end{array}$ & \multirow{2}{*}{ P-value } \\
\hline Mean \pm SD & $4.10 \pm 2.43$ & $6.80 \pm 3.32$ & \multirow{2}{*}{$0.008^{*}$} \\
\hline Median (Range) & $3.0(1.0-10.0)$ & $6.0(1.0-14.0)$ & \\
\hline
\end{tabular}



Fig.3. Duration of disease in both groups 


\section{Mean deviation results}

Group II had a considerably lower MD in SAP than group I $(\mathrm{p}=0.003)$

In SWAP, the MD in group II was considerably lower than in group I ( $\mathrm{p}$ value $=0.001)$.
MD was substantially lower in SWAP than SAP in group I $(\mathrm{P}=0.00009)$. In group II, the same results were obtained. Table 4 and Figure 4 009) demonstrate this. Group II follows the same path as group I. Table 4 and Figure 4 demonstrate this.

Table 4. MD results in both groups

\begin{tabular}{|c|c|c|c|}
\hline \multicolumn{1}{|c|}{ MD } & $\begin{array}{c}\text { Group I } \\
(\mathbf{n = 2 0})\end{array}$ & $\begin{array}{c}\text { Group II } \\
(\mathbf{n = 2 0})\end{array}$ & \multirow{2}{*}{ P-value $^{\mathbf{1}}$} \\
\cline { 1 - 3 } SAP: & $-3.28 \pm 1.83$ & $-6.26 \pm 3.07$ & \multirow{2}{*}{$0.003^{*}$} \\
\cline { 1 - 3 } Mean \pm SD & $-2.84(-9.5$ to -1.1$)$ & $-7.66(-11.3$ to 0.7$)$ & \multirow{2}{*}{$0.001^{*}$} \\
\cline { 1 - 3 } Median (Range) & $-8.12 \pm 2.16$ & $-11.86 \pm 3.64$ & \multirow{2}{*}{} \\
\cline { 1 - 3 } SWAP: & $-8.08(-13.5$ to -5.3$)$ & $-10.07(-17.2$ to 7.6$)$ & \\
\cline { 1 - 3 } Mean \pm SD & $0.00009^{*}$ & $0.00009^{*}$ & \\
\cline { 1 - 3 } Median (Range) $^{\text {P-value }^{2}}$ & & &
\end{tabular}

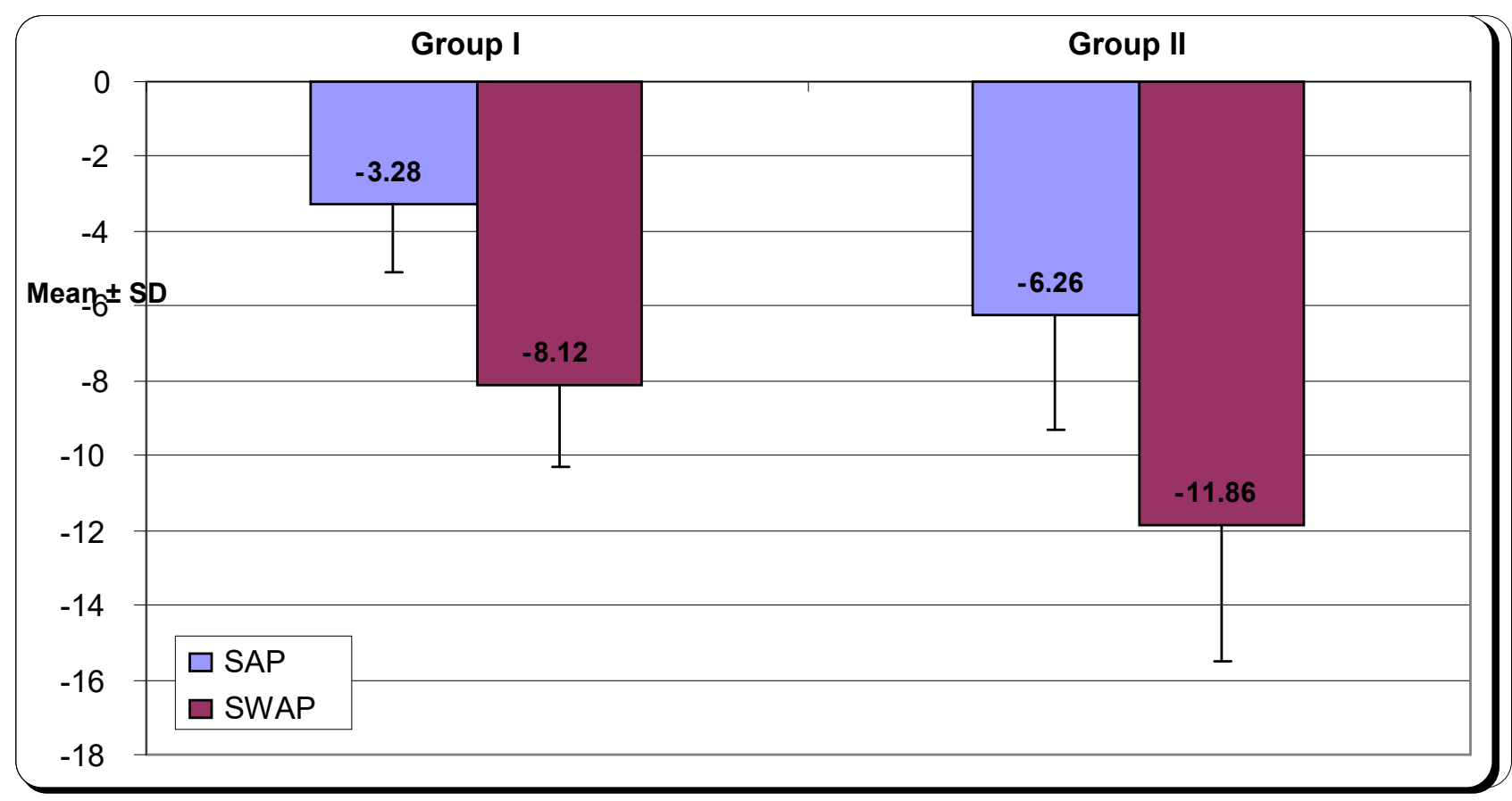

Fig.4. MD results in both groups

\section{CPSD results}

As shown in table 5 and figure 5, there was no statistically significant difference in CPSD of SAP group I and CPSD of SAP in group II, no statistically significant difference in CPSD of SWAP group I and CPSD of SWAP in group II, and no statistically significant difference in CPSD 
of SAP and CPSD of SWAP in group I or group II.

Table 5. CPSD results in both groups

\begin{tabular}{|c|c|c|c|}
\hline CPSD & $\begin{array}{l}\text { Group I } \\
(\mathbf{n}=\mathbf{2 0})\end{array}$ & $\begin{array}{l}\text { Group II } \\
(\mathbf{n}=\mathbf{2 0})\end{array}$ & P-value ${ }^{1}$ \\
\hline SAP: & & & \multirow{3}{*}{0.704} \\
\hline Mean \pm SD & $1.81 \pm 1.47$ & $3.20 \pm 3.91$ & \\
\hline Median (Range) & $1.37(0.0-5.8)$ & $2.02(0.0-11.9)$ & \\
\hline \multicolumn{3}{|l|}{ SWAP: } & \multirow{3}{*}{0.913} \\
\hline Mean \pm SD & $3.30 \pm 3.84$ & $2.25 \pm 1.59$ & \\
\hline Median (Range) & $2.32(0.0-14.9)$ & $2.57(0.0-5.4)$ & \\
\hline P-value $^{2}$ & 0.093 & 0.601 & \\
\hline
\end{tabular}



Fig.5. CPSD results in both groups

\section{Short term fluctuations results}

SAP SF was statistically greater in group II (2.51 1.05) than in group I (1.73 0.50) $(\mathrm{P}=$ 0.003). In terms of SWAP, however, there was no difference between groups I and II $(\mathrm{p}=0.223)$.

Table 6 and Figure 6 demonstrate this. 
Table 6. SF results in both groups

\begin{tabular}{|c|c|c|c|}
\hline SF & $\begin{array}{l}\text { Group I } \\
(\mathbf{n}=\mathbf{2 0})\end{array}$ & $\begin{array}{l}\text { Group II } \\
(\mathbf{n}=\mathbf{2 0})\end{array}$ & P-value ${ }^{1}$ \\
\hline SAP: & & & \multirow{3}{*}{$0.003 *$} \\
\hline Mean \pm SD & $1.73 \pm 0.50$ & $2.51 \pm 1.05$ & \\
\hline Median (Range) & $1.58(1.1-2.8)$ & $2.11(0.8-4.4)$ & \\
\hline SWAP: & & & \multirow{3}{*}{0.223} \\
\hline Mean \pm SD & $2.04 \pm 0.67$ & $2.31 \pm 0.69$ & \\
\hline Median (Range) & $2.01(1.1-3.3)$ & $2.38(0.8-3.1)$ & \\
\hline P-value ${ }^{2}$ & 0.156 & 0.550 & \\
\hline
\end{tabular}

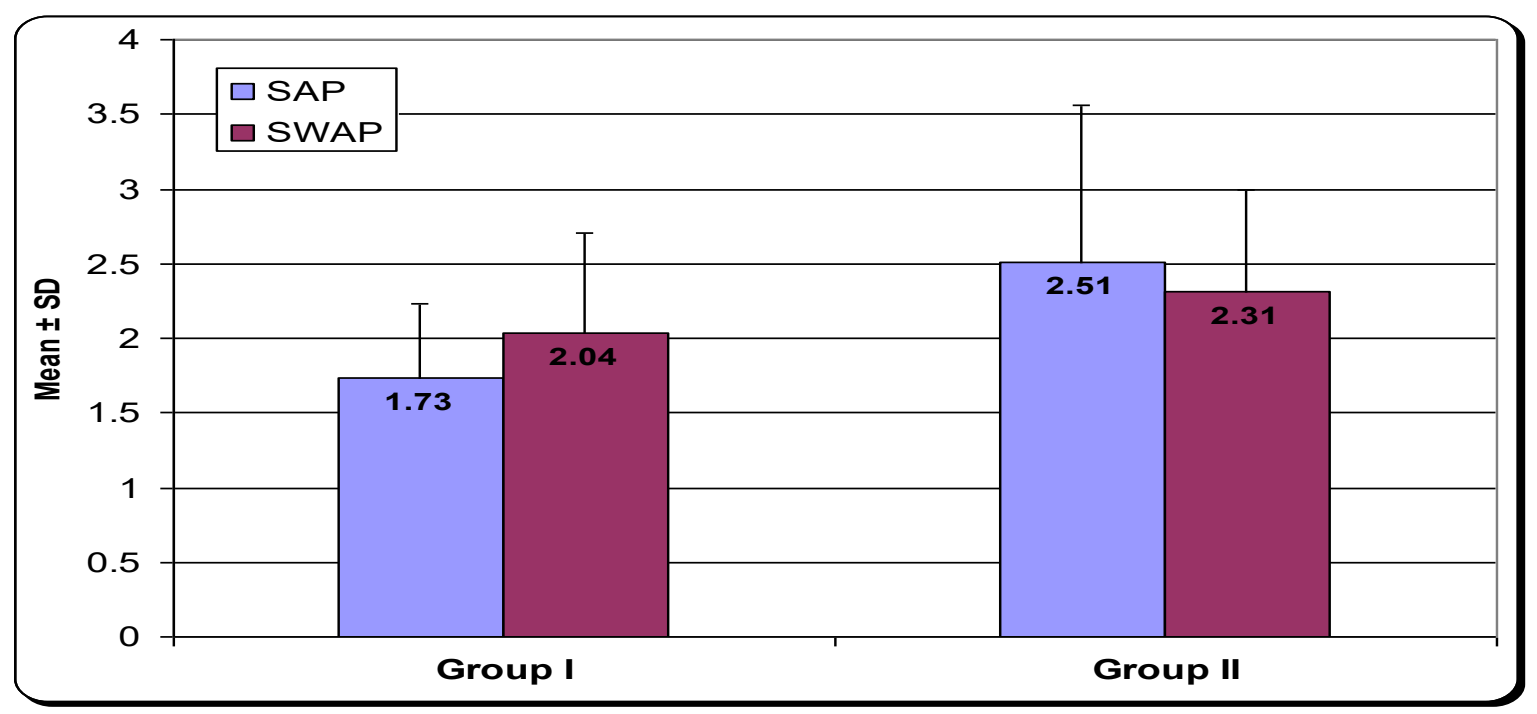

Fig.6. SF results in both groups

\section{Discussion}

In this study, we compared the utility of SWAP (blue on yellow) perimetry to SAP (white on white) perimetry in detecting changes in retinal sensitivity of the visual image in diabetic patients with and without retinopathy. The participants in our study ranged in age from 20 to 55 years old (means of $39.60 \pm 11.99$ SD years in group I and $43.95 \pm 12.27 \mathrm{SD}$ years in group
II).Between the two groups, there was no statistically significant difference.

In our study, the average duration of diabetes was $4.10 \pm 2.43 \mathrm{SD}$ years in group $\mathrm{I}$ and 6.80 3.32 SD years in group $\mathrm{II} \pm$ The difference between the two groups was statistically significant $(\mathrm{p}$ value $=0.008)$. On the other hand, (Nikki et al.,2016) discovered that the average duration of diabetes was $3.37 \pm 1.535$ years in eyes 
Hamed et al (2022)

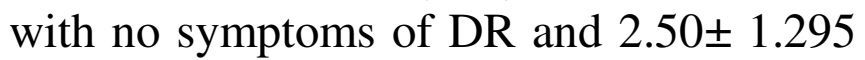
years in eyes with mild NPDR.

In SAP, group II's MD was considerably lower than group I's ( $p$ value $=0.003$ ).

In SWAP, MD in group II was considerably lower than in group I ( $p$ value $=0.001$ ).

MD was substantially lower in SWAP than SAP in group I $(P=0.00009)$. Group II follows the same path as group I.

Short-wavelength automated perimetry was also explored in patients with DM without macular edoema (Remky et al., 2003). For patients and subjects, SWAP mean sensitivity (MD) was considerably lower than SAP sensitivity (P0.0001). SWAP, he concluded, may serve as an early detector of visual function loss in early diabetic maculopathy, as well as a useful approach for predicting early diabetic macula damage and monitoring therapy. And while their results are similar to ours, we did not use an effect group. In addition, (Nitta et al., 2006) investigated the impact of clinical variables on

In our study there was no statistically significant difference in CPSD of SAP group I and CPSD of SAP in group II , there was no statistically significant difference in CPSD of SWAP group I and CPSD of SWAP in group II , also there was no statistically significant difference in CPSD of SAP and CPSD of SWAP neither in group I nor in group II and this is consistent with (Aydoğan et al.,2003)who found the averages of corrected pattern standard deviation (CPSD) in diabetics without retinopathy was $1.9 \pm 1.9 \mathrm{~dB}$. In diabetics with background retinopathy, was $2.8 \pm 2.7 \mathrm{~dB}$. The differences was statistically nonsignificant $(p>0.05)$ also.
SVU-IJMS, 5(1):210-218

SAP SF was statistically greater in group II $(2.51 \pm 1.05)$ than in group I $(1.73 \pm 0.50) \quad(P=0.003)$. In terms of SWAP, however, there was no significant difference between groups I and II ( $p=$ 0.223 ). Short fluctuation (SF) in SAP was statistically higher in group $2(2.86 \pm 1.23)$ than in group $1(2.100 \pm 0.76)(P=0.03)$, according to (Zico et al., 2016).

Between the two groups studied, SF revealed the same pattern of differences in SWAP.

\section{Conclusions}

The visual field may be affected by DR; such changes are visible in advanced stages of the disease. In DR, a varying amount of vision loss is typical, and it varies depending on the severity of the sickness.

We found that both systems SAP and SWAP can give adequate results with diabetic patients. Both tests with special relation to MD result can differentiate the patients with retinopathy from those without. However, SWAP technique was more sensitive and informative within the differentiation than SAP technique.

These findings were statistically significant and greatly in keeping with many other studies.

\section{References}

- AydoganN, PelitA,EvyrapanÖ,AkmanA， Göz ABD.(2003). Effects of background Diabetic retinopathy on visual field. Ret-vit, 10:164-169.

- Bayer AU, MaagKP, Erb, C. (2002). Detection of optic neuropathy in glaucomatous eyes with normal standard visual fields using a test battery of shortwavelength automated perimetry 
Hamed et al (2022)

and pattern electroretinography. Ophthalmology, 109(7), 1350-1361.

- HartWM, GordonMO. (1984). Color perimetry of glaucomatous visual field defects. Ophthalmology, 91(4), 338-346.

- JohnsonCA, Adams AJ, Casson EJ, and Brandt JD. (1993). Progression of early glaucomatous visual field loss as detected by blueon-yellow and standard white-onwhite automated perimetry, Arch. Ophthalmol , 651_111/ 656.

- Klein B.E. (2007). Overview of epidemiologic studies of diabetic retinopathy. Ophthalmic Epidemiol ,14:179-183.

- LiuS, LamS, Weinreb RN, YeC, CheungCY, Lai G, et al. (2011). Comparison of standard automated perimetry, frequency-doubling technology perimetry, and shortwavelength automated perimetry for detection of glaucoma. Investigative Opthalmology\& Visual Science, 52(10), 7325.

- Nikki

DS,AngbueTe, PearlM,Villalon T. (2016). Short Wavelength Automated Perimetry and Peripapillary Retinal Nerve Fiber Layer in Early

Diabetes.Philipp

Ophthalmol;41:32-38

- Nitta K, Saito

Y, KobayashiA,Sugiyama,

K.(2006). Influence of clinical factors on blue-on-yellow perimetry for diabetic patients without retinopathy: comparison with whiteon-white perimetry. Retina, 26(7):797-802.

- Remky A, Weber A, Hendricks S.(2003).
SVU-IJMS, 5(1):210-218

automated perimetry in patients with diabetes mellitus without macular edema. Graefes Arch Clin Exp Ophthalmol; 241:468-471.

- Ryan J,Fante BS.(2010). Diabetic Retinopathy: An Update on Treatment. The American Journal of Medicine ,123:213-216.

- Sample PA, WeinrebRN,Boynton RM. (1986). Blue-onyellow color perimetr. Supplement to Investigative Ophthalmology and Visual Science Philadelphia, JB Lippincott, p. 159.

- Sample PA, MartinezGA,WeinrebRN.(1993). Color visual fields. Mills.Kyoto Kugler. 473_476.

- Sample PA,Weinreb RN (1990).Color perimetry for assessment of primary open angle glaucoma, Invest. Ophthalmol.Vis.Sci, 31:1869_1875.

- Zico OA , EL Shazly AAF,Ahmed EEA.(2016).Short wavelength automated perimetry can detect visual field changes in diabetic patients without retinopathy,IJO., 62 (4) : 383 . 